\title{
Factors Associated with Non-Adherence to Antiretroviral Therapy among Adults living with HIV/AIDS in Arsi Zone, Oromia
}

\section{Dibaba $\mathbf{B}^{1 *}$ and Hussein $\mathbf{M}^{2}$}

${ }^{1}$ College of Health Sciences, Department of Public Health, Asella, Ethiopia

${ }^{2}$ Department of Pharmacy, Arsi University, Asella, Ethiopia

\begin{abstract}
Objective: To assess factors associated with non-adherence to antiretroviral therapy among adults living with HIV/ AIDS in Arsi zone.

Methods: This is a multiple facility-based cross-sectional study, where 306 adult aged over 18 years who were receiving antiretroviral therapy had interviewed using a structured questionnaire about their experience of taking antiretroviral therapy between June 1, 2015-June1, 2016. Additional data was extracted from each facilities record. Participants were defined as non-adherent if they missed at least one dose of their highly active antiretroviral therapy prescriptions within the last 30 days. Participants were also asked to indicate reasons for missing doses of highly active antiretroviral therapy. Descriptive analysis and Multivariable logistic regression model was used to determine predictors of non-adherence. The odds ratios in the binary logistic regression along with $95 \%$ confidence interval were used.
\end{abstract}

Results: Overall, 306 clients responded; $35 \%$ were non-adherent. Seventy five $(24.5 \%)$ and $214(69.9 \%)$ patients agreed and strongly agreed that the use of antiretroviral therapy is essential in their life. Thirty seven (12.1\%) do not know whether drug resistance develop when antiretroviral therapy are missed or not. The reasons for missing doses include forgetting $71(23.2 \%)$ and hiding from colleagues $90(29.4 \%)$. Respondents who reported hiding from colleagues were found to be 2 times more likely to be non-adherent to antiretroviral therapy compared to respondents who had not reported hiding from colleagues (adjusted odds ratio $=2.02 ; 95 \%$ Confidence interval: 1.19-3.43).

Conclusion: Prevalence of non-adherence to antiretroviral therapy is high. Some of the respondents do not know whether drug resistance develop when antiretroviral therapy are missed or not. Forgetfulness and hiding from colleague were the most common reason for missing doses. Hence, antiretroviral therapy counselors need to emphasis on memory aids. Creation of awareness on the risks of non-adherence is needed.

Keywords: Non-adherence; Antiretroviral therapy; HIV/AIDS care; Arsi zone, Oromia

\section{Introduction}

Antiretroviral therapy has been initiated to combat human immunedeficiency virus (HIV)/acquired immune-deficiency syndrome (AIDS). Antiretroviral therapy use has slowed disease progression, decreased mortality and improved the quality of life for many persons with HIV $[1,2]$. Antiretroviral therapy has improved the health of many human immunodeficiency virus (HIV) positive individuals who otherwise would have died. Treatment efficacy relies, however, on sustained adherence, which constitutes a serious challenge to those receiving antiretroviral therapy [3]. The regimens are often complicated and can include varying dosing schedules, dietary restrictions, and adverse effects [4].Consistently high levels of adherence are necessary for reliable viral suppression [5] and prevention of resistance [6], disease progression, and death [7]. Even though antiretroviral therapy is the single most dramatic development yet in the treatment of HIV/ AIDS, many have been described as inconsistent with their treatment regimens $[8,9]$.

Non-adherence is a risk factor for development of drug resistance [10]. A study done in China, Hunan Province found that all patients on antiretroviral therapy who reported missing a dose in the last 7 days had drug resistance mutations [6]. A study done in Swiss indicated that there was a significant association between optimal viral suppression and non adherence as well as a significant linear trend in optimal viral suppression by missed doses [11]. A study done in Swiss in 2015 explored the effect of non-adherence to antiretroviral therapy and found that the risk of viral failure (fail to suppress the virus) increased with each self-reported missed dose per 4 weeks and Self-report of two or more missed doses of antiretroviral therapy is associated with an increased risk of both viral failure and death [12].

Available data suggests that patients must take a high proportion (95\% or more) of antiretroviral drug doses to maintain suppression of viral replication $[13,14]$. However, many studies reported that a number of patients took less than $95 \%$ of antiretroviral therapy $[8,9]$. A study done in southwest Ethiopia in 2008 found that the prevalence of non adherence to antiretroviral therapy was $21 \%$ [15]. A study done in northwest Ethiopia in 2010 indicated that the prevalence of nonadherence was $17.3 \%$ [16]. A study done in Nigeria in 2008 found that the prevalence of non-adherence to antiretroviral therapy among adult person living with HIV/AIDS was 37.1\% [17]. A study done in Yaoundé, Cameroon in 2013 showed that the prevalence of non-adherence to

*Corresponding author: Bekele Dibaba (MPH), Lecturer in Arsi University College of Health Sciences, Department of Public Health, Asella, Ethiopia, Tel: +2510910955032; E-mail: fenetbekele@gmail.com

Received November 30, 2016; Accepted December 14, 2016; Published December 21, 2016

Citation: Dibaba B, Hussein M (2017) Factors Associated with Non-Adherence to Antiretroviral Therapy among Adults living with HIVIAIDS in Arsi Zone, Oromia. AIDS Clin Res 8: 647. doi:10.4172/2155-6113.1000647

Copyright: ( 2017 Dibaba B, et al. This is an open-access article distributed unde the terms of the Creative Commons Attribution License, which permits unrestricted use, distribution, and reproduction in any medium, provided the original author and source are credited. 
antiretroviral therapy was $34.9 \%$ [18]. These rates of non adherence can contribute to sub-optimal drug levels which can lead to drug resistance and increase mortality. One of the main factors contributing to suboptimal drug levels and resistance is non-adherence to treatment [19].

Understanding factors associated with poor adherence is essential to maximize virologic suppression and reduce mortality. Non adherence to antiretroviral therapy has been associated to diverse factors including patient related factors, health condition/disease, health care system/ health care team, therapy/treatment and socio-economic factors [2022]. Reasons for non-adherence are multi factorial. Age (younger), perceived treatment side effects, dosing frequency different from twice daily, a protease inhibitor-based regimen, depression and lack of support from the main partner were associated with non-adherence [23]. Similarly, a study done in Kenya found that younger respondents between 25 and 49 ages were more likely not to be non-adherent to highly active antiretroviral therapy [24]. Likewise, study done in selected hospitals from south and central Ethiopia found that being unmarried was associated with non-adherence [25].

A study done in Nepal indicated that the major reason for nonadherence was side effect of antiretroviral therapy drugs [26]. However, study done in North-West Ethiopia found that among reasons for missing doses were forgetfulness $29(43.3 \%)$ and side-effect of antiretroviral therapy drugs 2 (3\%) [27].

The above studies signified that the magnitudes of factors responsible for non adherence were dissimilar in different settings and different factors were associated with non adherence in dissimilar study area. Moreover, published data about factors that influence nonadherence to antiretroviral therapy in Oromia is limited. To generate this knowledge, this study determined factors associated with non adherence in Arsi zone, Oromia.

\section{Literature Review}

\section{Prevalence of non-adherence to antiretroviral therapy}

Antiretroviral therapy requires high-level (>95\%) adherence. However, non-adherence becomes a challenge. Significant proportions of HIV/AIDS patients attending the care do not reach high levels of adherence leading to viral resistance to the drug. A study done in Yaoundé, Cameroon in 2013 showed that the prevalence of nonadherence to antiretroviral therapy was $34.9 \%$ (18). A study done in Nigeria in 2008 found that the prevalence of non-adherence to antiretroviral therapy among adult person living with HIV/AIDS was $37.1 \%$ [17]. The prevalence non-adherence in Southwest Ethiopia in 2008 was $21 \%$ [15] and $22 \%$ in Cote d'Ivore [28]. A study done in Northwest Ethiopia in 2010 found that the prevalence of non-adherence was $17.3 \%[16]$.

\section{Socio-demographic factors and non-adherence to antiretroviral therapy}

Understanding factors associated with poor adherence is essential to maximize virology suppression and reduce mortality [29]. Factors associated with non-adherence varies with gender [30]. Study done among Brazilian patients indicated that the incidence of non-adherence was 1.5 times greater among women compared to men [31]. A study done in Kenya found that younger respondents between 25 and 49 ages were more likely not to be non-adherent to highly active antiretroviral therapy although age did not predict [24]. Similarly, younger individuals were associated with poor adherence [32]. Study done in selected hospitals from south and central Ethiopia found that being unmarried and alcohol drinking were associated with non-adherence [25]. However, a study found no association was observed between non-adherence to antiretroviral therapy and gender, age, marital status and educational level [33].

Employment status was associated with poor adherence and this may be corroborated by the major reason reported for non-adherence (busy at work or school) [34]. Living in isolation were significantly associated with non-adherence to antiretroviral therapy [35].

Study done in Kenya found that respondents who accessed therapy in clinics within a walking distance (5KM) from their homes were associated with non-adherence. These findings together with social stigma associated with antiretroviral therapy use suggested that most respondents who accessed free therapy in clinics within walking distance to their homes did so due to lack of choice; speculatively, could not afford transport cost to alternative health facility where antiretroviral therapy is given [24].

\section{Reasons for non-adherence to antiretroviral therapy}

A study done in Nigeria in 2013 indicated that common reasons for non-adherence were living far away from the medical centre $(8.1 \%)$ [36]. A study done in North-West Ethiopia showed that the reasons for missing doses were forgetfulness (43.3\%) and side-effect of antiretroviral therapy drugs (3\%) [27]. Study done in Addis Ababa, Ethiopia showed that the major reasons for non-adherence include simply forgot which was $33.9 \%$ [37]. Similarly, a study done in Harari showed that main reasons for non-adherence were forgetting (47.2\%) [38]. Likewise, study done in Nigeria in 2013 found that common reasons for non-adherence were forgetfulness (51.5\%) [36]. Study done in Tanzania showed that reasons for non-adherence were side effects of antiretroviral therapy drugs which was $53.3 \%$ and the side effects antiretroviral therapy drugs were found to be statistically significant [39]. Study done in Nepal indicated that among the reasons for non-adherence, side effect of antiretroviral therapy drug were mentioned [26].

\section{Side effects of antiretroviral drugs and non-adherence}

Non-adherence was independently associated with side effects of antiretroviral drugs [40]. Similarly, self-report of three or more adverse reactions were associated with an increased risk of non-adherence [41]. Likewise, medication side effects were a significant predictor of nonadherence in the sample at large and among women in particular [42]. Study done in Brazil in 2015 showed that adverse drug reaction was associated with non-adherence [43]

\section{Alcohol drinkers and non-adherence to antiretroviral therapy}

Study done in West Africa found association between hazardous drinkers and non-adherence [44]. Similarly, study done in Cameroon found that drinking alcohol was associated with non- adherence [9]. Alcohol use was associated with non- adherence to antiretroviral therapy among HIV infected people in Pwani Region, eastern Tanzania [45]. Likewise, study done in South Africa showed that alcohol use is independently associated with antiretroviral adherence [46]. Study done in South India also indicated the association of alcohol use with non-adherence [47]. Similarly, alcohol dependence was a significant predictor of non-adherence only in women [42]. Alcohol use were associated with an increased risk of non-adherence [41].

\section{Depression and non-adherence to antiretroviral therapy}

Study done in Southwest Ethiopia found that patients who were not depressed were two times more likely to be adherent than those who 
were depressed [15]. Similarly study done in United States indicated that being younger and greater risk of depression were associated with poorer adherence [48]. Likewise, study done in Nigeria among depressed HIV/AIDS patients indicated that depressive disorder in patients with HIV/AIDS is associated with poor adherence to antiretroviral medication [49]. A study done in South India indicated that depression was associated with lower adherence [50].

\section{Methodology}

\section{Setting}

This study was conducted in Arsi zone health facilities where antiretroviral therapy is given. Arsi zone located is in Oromia National Regional State. Arsi zone is 175 kilo-meter away from capital city of Ethiopia (Addis Ababa).

\section{Study population and period}

The study populations were HIV+ outpatients aged 18 years or more on free antiretroviral therapy for three or more months. The study was carried out between June 1, 2015-June 1, 2016.

\section{Study design}

Multiple facility-based cross-sectional observational study design

\section{Sample procedure and sample size calculation}

There were 29 health facilities which give antiretroviral service in Arsi zone (study setting). Out of the 29 health facilities 10 were randomly selected using lottery method. Then, the sample size was calculated using EPIINFO version: 7.2.0.1 STATCALC taking the average prevalence of non-adherence from recently done studies in different setting which was $23.7 \%$, a precision of $5 \%$ and with $95 \%$ confidence level. After adding $10 \%$ for non-response rate, an overall sample size of 306 was obtained. Next, the calculated sample size was proportionally allocated to each of the health facilities based on the number of clients on antiretroviral therapy in each of the health facilities. Later, systematic sampling methods were used to select the study subjects. That is, the number of clients on antiretroviral therapy in each of the health facility were divided to by the sample size proportional to every of the health facilities to get the interval and every that interval the study participants were selected as they visited the health facilities.

\section{Data collection method}

Data was collected from systematically selected persons attending HIV/AIDS care as they visited the health facilities for their antiretroviral treatment. Data on variables including non-adherence and associated factors were collected using an interviewer administered pretested questionnaire. The patients were interviewed about their highly active antiretroviral therapy beliefs, antiretroviral therapy intake and reasons for non-adherence. Additional data about the respondents' antiretroviral intake were extracted from hospital records.

\section{Data analysis and management}

Data generated from the questionnaire were entered into EPIINFO version 7.1.0.1 and exported to SPSS version 21 for analysis. Participants were defined as non-adherent if they missed at least one dose of their highly active antiretroviral therapy prescriptions within the last 30 days. Participants were also asked to indicate reasons for missing doses of highly active antiretroviral therapy. Descriptive statistics was done to assess basic client characteristics and proportion of non-adherence. Frequencies, cross-tabulations, chi-square test, and multivariate logistic regression were used to determine predicting factors. Binary logistic regression was done to determine statistical association between explanatory variables and non-adherence. All variables that were associated with non-adherence in binary logistic regression analyses were entered into multivariable logistic regression. P-values at the level of significance of $5 \%$ were considered statistically significant.

\section{Operational definition}

Non adherence is defined as self reported at least one missed doses of antiretroviral therapy in the last 30 days. This definition was generated because of fail to suppress the virus occurred among the patients who missed one dose per 4 weeks [12]. Moreover, other studies have used this definition to study non adherence [11,24].

\section{Ethical considerations}

Ethical clearance was given by Arsi University Ethical Review Committee, and permission to conduct the research was obtained from the participating health facilities. Consent was obtained both verbally and in written. To ensure confidentiality, interviews were conducted in private and strict control maintained over data.

\section{Results}

\section{Socio-demographic characteristics of the respondents}

Out of the 306 patients interviewed, all of them answered almost all the adherence questions and $35.2 \%$ were non-adherent. Males were 139 (45.4\%) and females 167 (54.5\%); their age were 18+ years. One hundred fifty (49\%) had primary education and $95(31 \%)$ had secondary education. Two hundred six (67.3\%) respondents earned less than 500 EBR per month and $71(23.2 \%)$ had monthly income of 5011000. Majority respondents $224(73.2 \%)$ had a current CD4 count of more than 200 cells/ml (mean CD4 count of 524.12). The initial mean CD4 count was 266.76 . Most 252(82.4\%) patients lived with family and $48(15.7 \%)$ live alone. Two hundred twenty two $(72.5 \%)$ reported getting social support (Table 1).

\section{Reasons for not taking antiretroviral therapy}

Among the reasons for missing doses were forgetting71 (23.2\%), hiding from colleagues 90 (29.4\%), drink alcohol 62(20.3\%) and side effect of antiretroviral therapy drugs 59 (19.3\%) (Table 2).

\section{Knowledge and belief about taking antiretroviral therapy medication}

Seventy five $(24.5 \%)$ and 214 (69.9\%) patients agreed and strongly agreed that the use of antiretroviral therapy is essential in their life. Respondents those agreed and strongly agreed that missing doses will determine the treatment were $70(22.9 \%)$ and $105(34.3 \%)$ respectively. Similarly respondents who agree and strongly agree that drug resistance develops when antiretroviral are missed were 92(30.1\%) and $163(53.3 \%)$ The time at which the medication is taken will influence its effectiveness were agreed and strongly agreed by respondents 122 (39.9\%) and 160(52.3\%) (Table 3).

\section{Association between Scio-demographic variables and non- adherence to antiretroviral therapy}

Multivariable logistic regression showed that there is no significant association between some socio-demographic variables and nonadherence to antiretroviral therapy at P-value of $<0.05$ (Table 4).

Association between reasons for not taking antiretroviral 
Citation: Dibaba B, Hussein M (2017) Factors Associated with Non-Adherence to Antiretroviral Therapy among Adults living with HIV/AIDS in Arsi Zone, Oromia. J AIDS Clin Res 8: 647. doi:10.4172/2155-6113.1000647

Page 4 of 8

\begin{tabular}{|c|c|c|c|c|c|c|c|}
\hline \multicolumn{2}{|l|}{ Variables } & \multicolumn{4}{|c|}{ Non-adherence } & \multirow{2}{*}{\multicolumn{2}{|c|}{ Total }} \\
\hline & & \multicolumn{2}{|l|}{ Yes } & \multicolumn{2}{|c|}{ No } & & \\
\hline & & Frequency & $\%$ & Frequency & $0 \%$ & Frequency & $\%$ \\
\hline \multirow[t]{3}{*}{ Gender } & Male & 46 & 43.0 & 93 & 46.7 & 139 & 45.4 \\
\hline & Female & 61 & 57.0 & 106 & 53.3 & 167 & 54.6 \\
\hline & Total & 107 & 100.0 & 199 & 100.0 & 306 & 100.0 \\
\hline \multirow[t]{5}{*}{ Age group } & $18-19$ & 0 & 0 & 2 & 1.0 & 2 & 0.7 \\
\hline & $20-24$ & 2 & 1.90 & 5 & 2.5 & 7 & 2.3 \\
\hline & $25-49$ & 92 & 86.0 & 170 & 85.4 & 262 & 85.6 \\
\hline & $>=50$ & 13 & 12.1 & 22 & 11.1 & 35 & 11.4 \\
\hline & Total & 107 & 100.0 & 199 & 100.0 & 306 & 100.0 \\
\hline \multirow{5}{*}{ Marital status } & never married & 67 & 6.5 & 134 & 9.0 & 201 & 8.2 \\
\hline & married & 24 & 62.6 & 30 & 67.3 & 54 & 65.7 \\
\hline & divorced/separated & 9 & 22.4 & 17 & 15.1 & 26 & 17.6 \\
\hline & widow/widower & 107 & 8.40 & 199 & 8.5 & 306 & 8.5 \\
\hline & Total & & 100.0 & & 100.0 & & 100.0 \\
\hline \multirow[t]{7}{*}{ Educational level } & No Education & 2 & 1.9 & 5 & 2.5 & 7 & 2.3 \\
\hline & Primary school & 59 & 55.1 & 91 & 45.7 & 150 & 49.0 \\
\hline & Secondary school & 30 & 28.0 & 65 & 32.7 & 95 & 31.0 \\
\hline & High school & 14 & 13.1 & 30 & 15.1 & 44 & 14.4 \\
\hline & vocational training & 2 & 1.9 & 7 & 3.5 & 9 & 2.9 \\
\hline & University & 0 & 0 & 1 & 0.5 & 1 & 0.3 \\
\hline & Total & 107 & 100.0 & 199 & 100.0 & 306 & 100.0 \\
\hline \multirow[t]{4}{*}{ Monthly income } & $<500$ & 76 & 71.0 & 130 & 65.3 & 206 & 67.3 \\
\hline & $501-1000$ & 24 & 22.4 & 47 & 23.6 & 71 & 23.2 \\
\hline & $1001-1500$ & 5 & 4.7 & 16 & 8.0 & 21 & 6.9 \\
\hline & $1501-2000$ & 0 & - & 4 & 2.0 & 4 & 1.3 \\
\hline \multirow[t]{2}{*}{ Monthly income } & $>2000$ & 2 & 1.9 & 2 & 1.0 & 4 & 1.3 \\
\hline & Total & 107 & 100.0 & 199 & 100.0 & 306 & 100.0 \\
\hline \multirow[t]{4}{*}{ Living with } & alone & 17 & 15.9 & 31 & 15.6 & 48 & 15.7 \\
\hline & family & 87 & 81.3 & 165 & 82.9 & 252 & 82.4 \\
\hline & other & 3 & 2.8 & 3 & 1.5 & 6 & 2.0 \\
\hline & Total & 107 & 100.0 & 199 & 100.0 & 306 & 100.0 \\
\hline \multirow[t]{4}{*}{ Use reminder } & Yes & 93 & 86.9 & 188 & 91.8 & 25 & 8.2 \\
\hline & No & 14 & 13.1 & 11 & 5.5 & 261 & 85.3 \\
\hline & Total & 107 & 100.0 & 199 & 100.0 & 306 & 100.0 \\
\hline & not at all & 2 & 1.9 & 3 & 1.5 & 5 & 1.6 \\
\hline \multirow[t]{4}{*}{ Level of reminder helped you } & a little & 9 & 8.4 & 1 & 0.5 & 10 & 3.3 \\
\hline & some what & 17 & 15.9 & 34 & 17.1 & 51 & 16.7 \\
\hline & a lot & 65 & 60.7 & 146 & 73.4 & 211 & 69.0 \\
\hline & Total & 107 & 100.0 & 199 & 100.0 & 306 & 100.0 \\
\hline \multirow{5}{*}{$\begin{array}{l}\text { How often did you follow dietary } \\
\text { instruction }\end{array}$} & always & 27 & 25.2 & 102 & 51.3 & 129 & 42.2 \\
\hline & some time & 76 & 71.0 & 93 & 46.7 & 169 & 55.2 \\
\hline & rarely & 1 & 0.9 & 0 & 0 & 1 & 0.3 \\
\hline & never & 3 & 2.8 & 4 & 2.0 & 7 & 2.3 \\
\hline & Total & 107 & 100.0 & 199 & 100.0 & 306 & 100.0 \\
\hline \multirow[t]{4}{*}{ Clinical character } & Mean CD4 count & \multicolumn{3}{|c|}{ Non adherent } & \multicolumn{3}{|c|}{ Adherent } \\
\hline & & Mean & Freque & $\%$ & Mean & Frequency & $\%$ \\
\hline & Initial & 117.4 & 74 & 34.1 & 176.1 & 143 & 65.9 \\
\hline & current & 183.4 & 78 & 34.8 & 340.7 & 146 & 65.2 \\
\hline
\end{tabular}

Table 1: Socio-demographic and clinical characteristics versus status of non-adherence among adults living with HIVIAIDS in Arsi zone, South-East Oromia, June 1, 2015-June1, 2016

\section{therapy and non-adherence to antiretroviral therapy}

Multivariable logistic regression showed that there is significant association between non-adherence to antiretroviral therapy and reasons for not taking antiretroviral therapy. Patients who had accessing antiretroviral therapy in a clinic within walking distance or $<5 \mathrm{~km}$ from home were found to be 1.7 times more likely to be non-adherent to antiretroviral therapy compared respondents who were far away from clinic or $>5 \mathrm{~km}$ (adjusted odds ratio $=1.73$; 95\% Confidence interval: 1.06-2.82). Likewise, patients who reported hide from colleagues were found to be 2 times more likely to be non-adherent to antiretroviral therapy compared to respondents who had not reported hide from 
Citation: Dibaba B, Hussein M (2017) Factors Associated with Non-Adherence to Antiretroviral Therapy among Adults living with HIV/AIDS in Arsi Zone, Oromia. J AIDS Clin Res 8: 647. doi:10.4172/2155-6113.1000647

colleagues (adjusted odds ratio $=2.02 ; 95 \%$ Confidence interval: 1.19 3.43) (Table 5).

\section{Discussion}

In this study the prevalence of non- adherence to antiretroviral therapy among adult person living with HIV/AIDS is 35\%. Consistent to our finding study done in Yaoundé, Cameroon in 2013 showed that the prevalence of non-adherence to antiretroviral therapy was $34.9 \%$ [18]. Study done in Nigeria in 2008 found that the prevalence of nonadherence to antiretroviral therapy among adult person living with

\begin{tabular}{|c|c|c|c|}
\hline \multicolumn{2}{|l|}{ Variable } & Frequency & Percent \\
\hline \multirow{3}{*}{ Drink alcohol } & no & 244 & 79.7 \\
\hline & yes & 62 & 20.3 \\
\hline & Total & 306 & 100.0 \\
\hline \multirow{3}{*}{ Felt depressed } & no & 255 & 83.3 \\
\hline & yes & 51 & 16.7 \\
\hline & Total & 306 & 100.0 \\
\hline \multirow{3}{*}{ Felt sick } & no & 251 & 82.0 \\
\hline & yes & 55 & 18.0 \\
\hline & Total & 306 & 100.0 \\
\hline \multirow{3}{*}{ Being busy and forgot } & no & 235 & 76.8 \\
\hline & yes & 71 & 23.2 \\
\hline & Total & 306 & 100.0 \\
\hline \multirow{3}{*}{ side effects } & no & 247 & 80.7 \\
\hline & yes & 59 & 19.3 \\
\hline & Total & 306 & 100.0 \\
\hline \multirow{3}{*}{ Hide from colleagues } & no & 216 & 70.6 \\
\hline & yes & 90 & 29.4 \\
\hline & Total & 306 & 100.0 \\
\hline
\end{tabular}

Table 2: Reasons for not taking antiretroviral therapy among adults living with HIV/ AIDS in Arsi zone, South-East Oromia, June 1, 2015-June1, 2016.
HIV/AIDS was 37.1\% [17]. A study done in southwest Ethiopia in 2008 indicated that the prevalence of non-adherence was $21 \%$ [15]. Similarly, a study done in northwest Ethiopia in 2010 found that the prevalence of non-adherence was $17.3 \%$ [16]. The inconsistency with these findings could be attributed to differences in assessment methods and treatment periods when antiretroviral therapy knowledge among patients and clinicians was low.

In this study no significant association seen between non- adherence to antiretroviral therapy among adult person living with HIV/AIDS and gender, age, marital status and educational level. Similarly, a study done in 2009 reported that no association was observed between nonadherence to antiretroviral therapy and gender, age, marital status and educational level [33]. However, study done in Kenya in 2011 found that younger respondents between 25 and 49 ages were more likely not to be non-adherent to highly active antiretroviral therapy [24]. A study done in 2007 showed that younger individuals were associated with poor adherence [32]. Better adherence among older adults may be explained by survivor effect in that, individuals who maintain greater compliance with treatment recommendations may actually outlive those who are non-adherent.

In our study marital status and alcohol use were not significantly associated with non-adherence to antiretroviral therapy among adult person living with HIV/AIDS. However, a study done in 2009 in selected hospitals from south and central Ethiopia found that being unmarried and alcohol drinking were associated with non-adherence [25]. This inconsistence could be due to differences in study periods.

In this study respondents who accessed therapy in clinics within a walking distance $(5 \mathrm{~km})$ from their homes were about 1.7 times more likely to be non-adherent than those who were far away from health facility where antiretroviral therapy is given $(>5 \mathrm{~km})$. Similarly, a study done in Kenya in 2011 indicated that accessing antiretroviral therapy in

\begin{tabular}{|c|c|c|c|}
\hline \multicolumn{2}{|l|}{ Variable } & \multirow{2}{*}{$\begin{array}{c}\text { Frequency } \\
75\end{array}$} & \multirow{2}{*}{$\begin{array}{c}\text { Percent } \\
24.5\end{array}$} \\
\hline I will take antiretroviral therapy for the rest of my life & agree & & \\
\hline & disagree & 1 & .3 \\
\hline & strongly agree & 214 & 69.9 \\
\hline & Total & 306 & 100.0 \\
\hline \multirow[t]{4}{*}{ Missing doses will determine if treatment works } & agree & 70 & 22.9 \\
\hline & don't know & 12 & 3.9 \\
\hline & strongly agree & 105 & 34.3 \\
\hline & Total & 306 & 100.0 \\
\hline \multirow[t]{4}{*}{ Drug resistance develop when antiretroviral are missed } & agree & 92 & 30.1 \\
\hline & don't know & 37 & 12.1 \\
\hline & strongly agree & 163 & 53.3 \\
\hline & Total & 306 & 100.0 \\
\hline \multirow[t]{5}{*}{ Some antiretroviral have to be taken with empty stomach others with food } & agree & 133 & 43.5 \\
\hline & disagree & 2 & .7 \\
\hline & don't know & 10 & 3.3 \\
\hline & strongly agree & 145 & 47.4 \\
\hline & Total & 306 & 100.0 \\
\hline \multirow[t]{4}{*}{ The time at which the medication is taken will influence its effectiveness } & agree & 122 & 39.9 \\
\hline & don't know & 9 & 2.9 \\
\hline & strongly agree & 160 & 52.3 \\
\hline & Total & 306 & 100.0 \\
\hline
\end{tabular}

Table 3: Knowledge and belief towards taking antiretroviral therapy among adults living with HIV/AIDS in Arsi zone, South-East Oromia, June 1, $2015-J u n e 1,2016$. 
Citation: Dibaba B, Hussein M (2017) Factors Associated with Non-Adherence to Antiretroviral Therapy among Adults living with HIV/AIDS in Arsi Zone, Oromia. J AIDS Clin Res 8: 647. doi:10.4172/2155-6113.1000647

Page 6 of 8

\begin{tabular}{|c|c|c|c|c|c|c|c|}
\hline \multirow[t]{3}{*}{ Variables } & & \multicolumn{4}{|c|}{ Non-adherence } & \multirow{3}{*}{$\begin{array}{l}95 \% \text { Confidence interval for } \\
\text { crude odds ratio }\end{array}$} & \multirow{3}{*}{$\begin{array}{l}95 \% \text { Confidence interval for } \\
\text { adjusted odds ratio }\end{array}$} \\
\hline & & \multicolumn{2}{|c|}{ Yes } & \multicolumn{2}{|c|}{ No } & & \\
\hline & & Frequency & $\%$ & Frequency & $\%$ & & \\
\hline \multirow[t]{2}{*}{ Gender } & male & 46 & 33.1 & 93 & 66.9 & $1.97(1.38-2.79)^{\star}$ & $0.99(0.59-1.68)$ \\
\hline & female & 61 & 36.5 & 106 & 63.5 & 1 & 1 \\
\hline \multirow[t]{4}{*}{ age } & $18-19$ & 0 & 0 & 2 & 100.0 & $7.39(0.10-532.23)$ & $4.42(0.52-373.15)$ \\
\hline & $20-24$ & 2 & 28.6 & 5 & 71.4 & $2.36(0.47-11.90)$ & $1.24(0.19-7.82)$ \\
\hline & $25-49$ & 92 & 35.1 & 170 & 64.9 & $1.81(1.41-2.34)^{\star}$ & $1.15(0.54-2.48)$ \\
\hline & $>=50$ & 13 & 37.1 & 22 & 62.9 & 1 & 1 \\
\hline \multirow[t]{4}{*}{ Marital status } & never married & 67 & 28.0 & 134 & 72.0 & $2.41(1.02-5.70)^{\star}$ & $1.49(0.43-5.15)$ \\
\hline & married & 24 & 33.3 & 30 & 66.7 & $1.95(1.46-2.61)^{\star}$ & $1.09(0.44-2.65)$ \\
\hline & divorced & 9 & 44.4 & 17 & 55.6 & $1.25(0.73-2.14)$ & $0.81(0.29-2.23)$ \\
\hline & widow & 107 & 34.6 & 199 & 65.4 & 1 & 1 \\
\hline \multirow[t]{5}{*}{ Educational level } & No Education & 2 & 28.6 & 5 & 71.4 & $2.50(0.48-12.90)$ & $1.10(0.10-11.21)$ \\
\hline & Primary school & 59 & 39.3 & 91 & 60.7 & $1.53(1.10-2.13)^{\star}$ & $0.63(0.12-3.29)$ \\
\hline & Secondary & 30 & 31.6 & 65 & 68.4 & $1.54(1.11-2.14)^{*}$ & $0.89(0.17-4.61)$ \\
\hline & High school & 14 & 31.8 & 30 & 68.2 & $2.16(1.40-3.33)^{\star}$ & $0.70(0.12-4.01)$ \\
\hline & College/v & 2 & 22 & 8 & 80 & 1 & 1 \\
\hline \multirow[t]{4}{*}{ Monthly income } & $<500$ & 76 & 36.9 & 130 & 63.1 & $1.71(1.28-2.27)^{*}$ & $0.69(0.10-4.50)$ \\
\hline & $501-1000$ & 24 & 33.8 & 47 & 66.2 & $1.95(1.19-3.20)^{\star}$ & $0.76(0.11-5.18)$ \\
\hline & $1001-1500$ & 5 & 23.8 & 16 & 76.2 & $3.20(1.17-8.73)^{*}$ & $1.08(0.13-8.55)$ \\
\hline & $>1500$ & 2 & 25.0 & 6 & 75.0 & 1 & 1 \\
\hline \multirow[t]{3}{*}{ Living with } & Live alone & 17 & 35.4 & 31 & 64.6 & $1.79(0.99-3.23)$ & $1.87(0.34-10.12)$ \\
\hline & family & 87 & 34.5 & 165 & 65.5 & $1.86(1.43-2.41)^{\star}$ & $1.63(0.32-8.19)$ \\
\hline & other & 3 & 50.0 & 3 & 50.0 & 1 & 1 \\
\hline
\end{tabular}

Table 4: Association between some socio-demographic variables and non-adherence to antiretroviral therapy among adults living with HIVIAIDS in Arsi zone, SouthEast Oromia, June 1, 2015-June 1, 2016

*Statistically significant in crude odds ratio: P-value $<0.05$

\begin{tabular}{|c|c|c|c|c|c|c|c|}
\hline \multirow{3}{*}{\multicolumn{2}{|c|}{ Variables }} & \multicolumn{4}{|c|}{ Non-adherence } & \multirow{3}{*}{$\begin{array}{l}95 \% \text { Confidence interval } \\
\text { for crude odds ratio }\end{array}$} & \multirow{3}{*}{$\begin{array}{l}95 \% \text { Confidence interval for } \\
\text { adjusted odds ratio }\end{array}$} \\
\hline & & \multicolumn{2}{|c|}{ Yes } & \multicolumn{2}{|c|}{ No } & & \\
\hline & & Frequency & $\%$ & Frequency & $\%$ & & \\
\hline \multirow{2}{*}{$\begin{array}{l}\text { Distance from health } \\
\text { facility }\end{array}$} & $<5 \mathrm{~km}$ & 30 & 30.9 & 67 & 69.1 & $2.23(1.45-3.43)^{*}$ & $1.73(1.06-2.82)^{\star *}$ \\
\hline & $>5 \mathrm{~km}$ & 77 & 36.8 & 132 & 63.2 & 1 & 1 \\
\hline \multirow[t]{2}{*}{ Forget } & yes & 31 & 43.7 & 40 & 56.3 & $1.29(0.81-2.06)$ & $0.35(0.14-0.88)$ \\
\hline & no & 76 & 32.3 & 159 & 67.7 & 1 & 1 \\
\hline \multirow[t]{2}{*}{ Side-effects } & yes & 22 & 50.0 & 37 & 50.0 & $1.00(0.14-7.09)$ & $0.32(0.04-2.83)$ \\
\hline & no & 85 & 34.8 & 162 & 65.2 & 1 & 1 \\
\hline \multirow{6}{*}{$\begin{array}{l}\text { How often did you } \\
\text { drink alcohol }\end{array}$} & daily $>3$ & 1 & 33.3 & 2 & 66.7 & $2.00(0.18-22.06)$ & $1.66(0.14-18.92)$ \\
\hline & daily $<3$ & 8 & 88.9 & 1 & 11.1 & $0.13(0.02-0.99)$ & $0.07(0.01-0.61)$ \\
\hline & weekly $<5$ & 3 & 60.0 & 2 & 40.0 & $0.67(0.11-3.99)$ & $0.67(0.09-4.63)$ \\
\hline & occasionally & 6 & 31.6 & 13 & 68.4 & $2.17(0.82-5.70)$ & $1.77(0.62-5.05)$ \\
\hline & rarely occasionally & 26 & 34.7 & 49 & 65.3 & $1.89(1.17-3.02)^{*}$ & $1.47(0.86-2.51)$ \\
\hline & never & 63 & 32.3 & 132 & 67.7 & 1 & 1 \\
\hline \multirow[t]{2}{*}{ Hide from colleagues } & yes & 27 & 29.9 & 63 & 70.1 & $1.70(1.29-2.24)^{*}$ & $2.02(1.19-3.43)^{\star *}$ \\
\hline & no & 80 & 37.0 & 136 & 63.0 & 1 & 1 \\
\hline \multirow[t]{2}{*}{ depressed } & yes & 16 & 31.4 & 35 & 68.6 & $2.19(1.21-3.95)^{\star}$ & $5.43(0.89-33.06)$ \\
\hline & no & 91 & 35.7 & 164 & 64.3 & 1 & 1 \\
\hline \multirow[t]{2}{*}{ sick } & yes & 19 & 34.5 & 36 & 65.5 & $1.89(1.09-3.30)^{*}$ & $0.93(0.19-4.54)$ \\
\hline & no & 88 & 35.1 & 163 & 64.9 & 1 & 1 \\
\hline
\end{tabular}

Table 5: Association between non-adherence and reasons for not taking antiretroviral therapy among adults living with HIVIAIDS in Arsi zone, South-East Oromia, June 1, 2015-June 1, 2016.

*Statistically significant in crude odds ratio: P-value $<0.05$. ** Statistically significant in adjusted odds ratio: $\mathrm{P}$-value $<0.05$

a clinic within walking distance from home $(\mathrm{OR}=2.387$, CI.95 $=1.155$ 4.931; $\mathrm{p}=0.019)$ predicted non-adherence [24]. These findings together with social stigma associated with antiretroviral therapy use suggested that most respondents who accessed free therapy in clinics within walking distance to their homes did so due to lack of choice; speculatively, could not afford transport cost to alternative health facility where antiretroviral therapy is given. Inconsistence to our finding, study done in Nigeria in 2013 indicated that common reasons for non-adherence were living far away from the medical centre $(8.1 \%)$ [36]. The Inconsistence could be due to difference in socio-cultural factors among the study settings.

In this study $75(24.5 \%)$ and $214(69.9 \%)$ patients agreed and 
strongly agreed that the use of antiretroviral therapy is essential in their life. However, study done in North-West Ethiopia in 2015 found that $340(96.9 \%)$ patients agreed and strongly agreed that the use of antiretroviral therapy is essential in their life [27]. The inconsistence could be due to difference in awareness among person living with HIV/AIDS at the two study settings. That is, the participants of the northwest Ethiopia study were hospitalized patients who might have more awareness about the use of antiretroviral therapy.

In this study among the reasons for missing antiretroviral therapy doses were forgetting $71(23.2 \%)$ and side effect of antiretroviral therapy drugs 59 (19.3\%). Similarly, a study done in North-West Ethiopia indicated that the reasons for missing doses were forgetfulness $29(43.3 \%)$ and side-effect of antiretroviral therapy drugs were $2(3 \%)$ (27). Likewise, a study done in Addis Ababa, Ethiopia showed that the major reasons for non-adherence include simply forgot (33.9\%) (37). A study done in Harari showed that main reasons for non-adherence were forgetting (47.2\%) (38). Likewise, study done in Nigeria in 2013 found that common reasons for non-adherence were forgetfulness (51.5\%) [36].

In our study the adverse effects antiretroviral therapy reported by the respondents did not significantly influence non-adherence. However, Study done in Brazil in 2015 showed that adverse drug reaction was associated with non-adherence [43]. A study done in Tanzania in 2011 showed that reasons for non-adherence were side effects of antiretroviral therapy drugs which was $53.3 \%$ and the side effects antiretroviral therapy drugs were found to be statistically significant [39]. Similarly, a study done in 2009 indicated that non-adherence was independently associated with side effects of antiretroviral drugs [40]. Likewise, study done in 2005 showed that self-report of three or more adverse reactions were associated with an increased risk of non-adherence [41]. The possible explanations have to be explored.

In this study drinking alcohol was not associated with nonadherence to antiretroviral therapy. However, study done in Cameroon found that drinking alcohol was associated with non- adherence [9]. A study done in South India also indicated the association of alcohol use with non-adherence [47]. A study done in London showed that alcohol use were associated with an increased risk of non-adherence [41]. The inconsistence could be due to differences in study settings.

Our study indicated that depression was not significantly associated with non-adherence to antiretroviral therapy. However, a study done in Nigeria among depressed HIV/AIDS patients indicated that depressive disorder in patients with HIV/AIDS is associated with poor adherence to antiretroviral medication [49]. A study done in South India indicated that depression was associated with lower adherence [50]. This inconsistence may be due to differences in proportion of depressed patients among the studies.

\section{Conclusion}

The above studies indicated that the magnitudes of factors responsible for non adherence were dissimilar in different settings. Similarly, the above studies had pointed out that different factors have been associated with non adherence to antiretroviral therapy in different settings though there are few similarities. Given a complex array of factors associated with non adherence, no single strategy is likely to be effective for every patient who is non adherent to antiretroviral therapy. Our study has determined the major factors associated with non adherences which include hiding from colleague and forgetfulness. So, strategy to reduce non adherence in the study area can focus on these factors.
The finding of this study should be interpreted with some limitations because our measurement of non adherence was only based on participants' declaration of missed doses. Recall bias was also the possible bias that may encounter this study. Despite the above limitations, the study addressed several variables that predict non adherence and to fully characterize the study population, we extracted additional data from participants' record.

\section{Acknowledgement}

Our deepest gratitude goes to all data collectors and Respondents. Our sincere appreciation goes to our family for their time and continuous encouragement during the whole period of this work.

\section{Authors Contribution}

Bekele Dibaba carried out the research from conception to the write up of the final article. Mohammed Hussein is a principal researcher. He was participated in developing the proposal and supervised during data collection.

\section{References}

1. Okonji JA, Zeh C, Weidle PJ, Williamson J, Akoth B, et al. (2012) CD4, viral load response, and adherence among antiretroviral-naive breast-feeding women receiving triple antiretroviral prophylaxis for prevention of mother-tochild transmission of HIV in Kisumu, Kenya. J Acquir Immune Defic Syndr 61: 249-257.

2. Knobel H, Guelar A, Carmona A, Espona M, Gonzalez A, et al. (2001) Virologic outcome and predictors of virologic failure of highly active antiretroviral therapy containing protease inhibitors. AIDS Patient Care STDS 15: 193-199.

3. Meresse M, March L, Kouanfack C, Bonono RC, Boyer S, et al. (2014) Patterns of adherence to antiretroviral therapy and HIV drug resistance over time in the Stratall ANRS 12110/ESTHER trial in Cameroon. HIV Med 15: 478-487.

4. Bezabhe WM, Chalmers L, Bereznicki LR, Peterson GM, Bimirew MA, et al (2012) Barriers and facilitators of adherence to antiretroviral drug therapy and retention in care among adult HIV-positive patients: A qualitative study from Ethiopia. PLoS One 9: e97353.

5. Lamiraud K, Moatti JP, Raffi F, Carrieri MP, Protopopescu C, et al. (2012) Adherence to and effectiveness of highly active antiretroviral treatment for HIV infection: Assessing the bidirectional relationship. Med Care 50: 410-418.

6. Chen X, Zou X, He J, Zheng J, Chiarella J, et al. (2016) HIV drug resistance mutations (DRMs) detected by deep sequencing in virologic failure subjects on therapy from Hunan province, China. PLoS One 11: e0149215.

7. Liao L, Xing H, Su B, Wang Z, Ruan Y, et al. (2012) Impact of HIV drug resistance on virologic and immunologic failure and mortality in a cohort of patients on antiretroviral therapy in China. AIDS 27: 1815-1824.

8. Moore DM, Zhang W, Yip B, Genebat M, Lima VD, et al. (2010) Non-medically supervised treatment interruptions among participants in a universally accessible antiretroviral therapy programme. HIV Med 11: 299-307.

9. Boyer S, Clerc I, Bonono CR, Marcellin F, Bilé PC, et al. (2011) Non-adherence to antiretroviral treatment and unplanned treatment interruption among people living with HIVIAIDS in Cameroon: Individual and healthcare supply-related factors. Social Science and Medicine 72: 1383-1392.

10. Machado-Alba JE, González-Santos DM, Vidal-Guitart X (2011) Effectiveness of antiretroviral treatment in patients from Pereira and Manizales. Rev Salud Publica (Bogota) 13: 492-503.

11. Glass TR, De Geest S, Weber R, Vernazza PL, Rickenbach M, et al. (2006) Correlates of self-reported non-adherence to antiretroviral therapy in HIVinfected patients: The Swiss HIV Cohort Study. J Acquir Immune Defic Syndr 41: 385-392.

12. Glass TR, Sterne JA, Schneider MP, De Geest S, Nicca D, et al. (2015) Selfreported non-adherence to antiretroviral therapy as a predictor of viral failure and mortality. AIDS 29: 2195-2200.

13. El-Khatib Z, Ekstrom AM, Ledwaba J, Mohapi L, Laher F, et al. (2010) Viremia and drug resistance among HIV-1 patients on antiretroviral treatment: A crosssectional study in Soweto, South Africa. AIDS 24: 1679-1687.

14. Carrieri MP, Raffi F, Lewden C, Sobel A, Michelet C, et al. (2003) Impact of early versus late adherence to highly active antiretroviral therapy on immunovirological response: A 3 year follow-up study. Antivir Ther 8: 585-594. 
Citation: Dibaba B, Hussein M (2017) Factors Associated with Non-Adherence to Antiretroviral Therapy among Adults living with HIV/AIDS in Arsi Zone, Oromia. J AIDS Clin Res 8: 647. doi:10.4172/2155-6113.1000647

15. Amberbir A, Woldemichael K, Getachew S, Girma B, Deribe K (2008) Predictors of adherence to antiretroviral therapy among HIV-infected persons: A prospective study in Southwest Ethiopia. BMC Public Health 8: 265

16. Tessema B, Biadglegne F, Mulu A, Getachew A, Emmrich F, et al. (2010) Magnitude and determinants of nonadherence and nonreadiness to highly active antiretroviral therapy among people living with HIVIAIDS in Northwest Ethiopia: A cross-sectional study. AIDS Res Ther 7: 2

17. Olowookere SA, Fatiregun AA, Akinyemi JO, Bamgboye AE, Osagbemi GK (2008) Prevalence and determinants of nonadherence to highly active antiretroviral therapy among people living with HIVIAIDS in Ibadan, Nigeria. The Journal of Infection in Developing Countries 2: 369-372.

18. Pefura-Yone EW, Soh E, Kengne AP, Balkissou AD, Kuaban C (2013) Nonadherence to antiretroviral therapy in Yaounde: Prevalence, determinants and the concordance of two screening criteria. Journal of Infection and Public Health 6: 307-315.

19. Yuan $Y$, Xing H, Wang XY, Liu CH, Yang LT, et al. (2011) The prevalence of HIV1 drug resistance and associated factors in AIDS patients receiving HAART in Zhecheng county, Henan province. Zhonghua Yu Fang Yi Xue Za Zhi 45: 619-624.

20. Byakika-Tusiime J OJ, Tumwikirize WA, Katabira ET, Mugyenyi PN, Bangsberg DR (2005) Adherence to HIV antiretroviral therapy in HIV+ Ugandan patients purchasing therapy. International Journal of STD and AIDS 16: 38-41.

21. Carballo E C-SC, Carrera I, Fraga J, De La Fuente J, Ocampo A, et al. (2004) Assessing relationships between health-related quality of life and adherence to antiretroviral therapy. Qual Life Res 13: 587-589.

22. Murri R AA, Trotta MP, De Luca A, Melzi S, Minardi C, et al. (2004) Patientreported and physician-estimated adherence to HAART: Social and clinic center-related factors are associated with discordance. J Gen Intern Med 19: $1104-1110$.

23. Carrieri MP, Leport C, Protopopescu C, Cassuto JP, Bouvet E, et al. (2006) Factors associated with nonadherence to highly active antiretroviral therapy: $A$ 5 year follow-up analysis with correction for the bias induced by missing data in the treatment maintenance phase. J Acquir Immune Defic Syndr 41: 477-485.

24. Wakibi SN, Ng'ang'a ZW, Mbugua GG (2011) Factors associated with nonadherence to highly active antiretroviral therapy in Nairobi, Kenya. AIDS Res Ther 8: 43.

25. Beyene KA, Gedif T, Gebre-Mariam T, Engidawork E (2009) Highly active antiretroviral therapy adherence and its determinants in selected hospitals from south and central Ethiopia. Pharmacoepidemiol Drug Saf 18: 1007-1015.

26. Wasti SP, Simkhada P, Randall J, Freeman JV, van Teijlingen E (2012) Factors influencing adherence to antiretroviral treatment in Nepal: A mixed-methods study. PLoS One 7: e35547.

27. Tsega B, Srikanth BA, Shewamene Z (2015) Determinants of non-adherence to antiretroviral therapy in adult hospitalized patients, Northwest Ethiopia. Patient Prefer Adherence 9: 373-380.

28. Eholié S-P, Tanon A, Polneau S, Ouiminga M, Djadji A, et al. (2007) Field adherence to highly active antiretroviral therapy in HIV-infected adults in Abidjan, Côte d'Ivoire. J Acquir Immune Defic Syndr 45: 355-358.

29. Parruti G, Manzoli L, Toro PM, D'Amico G, Rotolo S, et al. (2006) Long-term adherence to first-line highly active antiretroviral therapy in a hospital-based cohort: Predictors and impact on virologic response and relapse. AIDS Patient Care and STDs 20: 48-56.

30. Peretti-Watel P, Spire B, Schiltz MA, Bouhnik AD, Heard I, et al. (2006) Vulnerability, unsafe sex and non-adherence to HAART: Evidence from a large sample of French HIVIAIDS outpatients. Social Science and Medicine 62: 2420-2433.

31. Bonolo PdF, Ceccato MdGB, Rocha GM, Acúrcio FdA, Campos LN, et al (2013) Gender differences in non-adherence among Brazilian patients initiating antiretroviral therapy. Clinics (Sa o Paulo, Brazil) 68: 612-620.

32. Barclay TR, Hinkin CH, Castellon SA, Mason KI, Reinhard MJ, et al. (2007) Age-associated predictors of medication adherence in HIV-positive adults: Health beliefs, self-efficacy and neurocognitive status. Health psychology 26 : 40-49.

33. Silva MrCF, Ximenes RADA, Miranda Filho DcB, Arraes LWDMS, Mendes M et al. (2009) Risk-factors for non-adherence to antiretroviral therapy. Revista do Instituto de Medicina Tropical de Sao Paulo 51: 135-139.
34. Ka A, Okojie O, Oqua D, Rc K, Omonaiye O, et al. (2011) Medication adherence and risk factors for non-adherence among patients taking highly active antiretroviral therapy. West African Journal of Pharmacy 22: 19-26.

35. Nakimuli-Mpungu E (2009) Psychological distress as a risk factor for nonadherence to highly active anti-retroviralltherapy. 11th Anniversary Annual International Meeting of the Institute of Human Virology Baltimore, MD United States 51: 155.

36. Pennap GR, Abdullahi U, Bako la (2013) Adherence to highly active antiretroviral therapy and its challenges in people living with human immunodeficiency virus (HIV) infection in Keffi, Nigeria. Journal of AIDS and HIV Research 5: 52-28.

37. Tadios Y, Davey G (2006) Antiretroviral treatment adherence and its correlates in Addis Ababa, Ethiopia. Ethiopian Medical Journal 44: 237-244.

38. Mitiku H, Abdosh T, Teklemariam Z (2013) Factors affecting adherence to antiretroviral treatment in harari national regional state, eastern Ethiopia. ISRN AIDS 2013: 960954

39. Baltazary G, Akarro RRJ, Mussa AS (2011) Some factors associated with non-adherence to antiretroviral therapy (ART) in people living with HIVIAIDS (PLHA) in Tanzania: A case study of Dar es Salaam region. East African Journal of Public Health 8: 237-246.

40. Protopopescu C, Raffi F, Roux P, Reynes J, Dellamonica P, et al. (2009) Factors associated with non-adherence to long-term highly active antiretroviral therapy: A 10 year follow-up analysis with correction for the bias induced by missing data. J Antimicrob Chemother 64: 599-606.

41. Bonolo PdF, César CC, Acúrcio FA, Ceccato MdGB, de Pádua CAM, et al. (2005) Non-adherence among patients initiating antiretroviral therapy: A challenge for health professionals in Brazil. AIDS 19: S5-S13.

42. Applebaum AJ, Richardson MA, Brady SM, Brief DJ, Keane TM (2009) Gender and other psychosocial factors as predictors of adherence to highly active antiretroviral therapy (HAART) in adults with comorbid HIVIAIDS, psychiatric and substance-related disorder. AIDS and Behavior 13: 60-65.

43. Silva JAG, Dourado I, Brito AMd, Silva CALd (2015) Factors associated with non-adherence to antiretroviral therapy in adults with AIDS in the first six months of treatment in Salvador, Bahia State, Brazil. Cadernos de saude publica 31: 1188-1198.

44. Jaquet A, Ekouevi DK, Bashi J, Aboubakrine M, Messou E, et al. ( 2010) Alcohol use and non-adherence to antiretroviral therapy in HIV-infected patients in West Africa. Addiction 105: 1416-1421.

45. Idindili B, Jullu B, Mugusi F, Tanner M (2012) A case-control study of factors associated with non-adherent to antiretroviral therapy among HIV infected people in Pwani Region, eastern Tanzania. Tanzania Journal of Health Research 14.

46. Morojele NK, Kekwaletswe CT, Nkosi S (20140 Associations between alcoho use, other psychosocial factors, structural factors and antiretroviral therapy (ART) adherence among South African ART recipients. AIDS and Behavior 18: 519-524.

47. Venkatesh KK, Srikrishnan AK, Mayer KH, Kumarasamy N, Raminani S, et al. (2010) Predictors of nonadherence to highly active antiretroviral therapy among HIV-infected South Indians in clinical care: Implications for developing adherence interventions in resource-limited settings. AIDS Patient Care STDS 24: 795-803.

48. Royal SW, Kidder DP, Patrabansh S, Wolitski RJ, Holtgrave DR, et al. (2009) Factors associated with adherence to highly active antiretroviral therapy in homeless or unstably housed adults living with HIV. AIDS Care 21: 448-455.

49. Olisah VO, Baiyewu O, Sheikh TL (2010) Adherence to highly active antiretroviral therapy in depressed patients with HIVIAIDS attending a Nigerian university teaching hospital clinic. African Journal of Psychiatry 13: 275-279.

50. Kleinman NJ, Manhart LE, Mohanraj R, Kumar S, Jeyaseelan L, et al. (2015) Antiretroviral therapy adherence measurement in non-clinical settings in South India. AIDS Care 27: 248-254. 